\title{
FEM simulation of bending and torsion tests of similar size RHS but of the different production options
}

\author{
Volodymyr Kukhar ${ }^{1, *}$, Yurii Sahirov ${ }^{1}$, Vadym Hornostai $^{2}$, Oleg Markov $^{3}$, and Mykyta Nahnibeda ${ }^{1}$ \\ 1 Pryazovskyi State Technical University, Universytetska str., 7, Mariupol, 87555, Ukraine \\ ${ }^{2}$ National Technical University of Ukraine "Igor Sikorsky Kyiv Polytechnic Institute", Peremohy ave., 37, Kyiv, 03056, Ukraine \\ ${ }^{3}$ Donbass State Engineering Academy, Akademichna str., 72, Kramatorsk, 84313, Ukraine
}

\begin{abstract}
The paper implements a method for analyzing the stress-strain state of rectangular hollow sections (RHS) by finite-element modeling (FEM) of tests for three-point bending and torsion. Design schemes, 3-D solid-state and deformable models have been developed using the automated analysis and CAD/CAE system software, made it possible to obtain equivalent stress distributions and displacements in models. A simulation of tests for RHS with a cross section of $40 \mathrm{~mm} \times 50 \mathrm{~mm}$, manufactured in two ways, was carried out: (a) by direct-forming of galvanized steel strips on roll-forming mill in a semi-closed section with a longitudinal gap of $0.5 \mathrm{~mm}$ between the edges formed on a $40 \mathrm{~mm}$ web (DF-RHS); (b) similar directforming to the closed section and next welding the edges to a longitudinal weld along the web middle of $50 \mathrm{~mm}$ (DFW-RHS). RHS with various wall thicknesses $(\mathrm{t}=1.93 \mathrm{~mm}, 1.84 \mathrm{~mm}$ and $0.7 \mathrm{~mm}$ ) was investigated, given the design features that depend on the manufacturing processes of structural sections. It was found DFW-RHS is stiffer by at least $50 \%$ compared to DF-RHS, which allows to savings the metal by reducing the RHS wall thickness by $62 \%$ while maintaining the same stiffness and ensuring high strength of structural section.
\end{abstract}

\section{Introduction}

Rectangular hollow sections (RHS) are great importance for much purposes, such as construction (load-bearing frames, columns, posts) and reinforced concrete structures, uPVC window systems of buildings and constructions, some areas of civil or mechanical engineering, shipbuilding, etc. [1-3]. Due to the prevalence and increasing demand for structural section, the requirements for the geometric parameters and strength of such products are becoming more stringent, for that the different standards have been developed in the European Union [4, 5] and most developed world countries $[1,4]$.

For the manufacture of structural sections with required service properties different fabrication methods are used [1, 6-12]: skew roll piercing process, pilger process, Fretz-Moon pipe process, induction welding process, spirally bent strip welding. Hot-finished process (HFP) [13-16] and cold-formed process (CFP) [7, 10$12]$ is the most common manufacturing for RHS. These consist in the roll-forming of circular tube from a strip, welding of edges and re-forming into rectangular tube section (round to square or rectangular section forming) with heating (HFP) or without heating (CFP), respectively. Recently, the direct-forming process (DFP) $[13,17]$ for RHS has been very justified and economical. This process of directly forming to square or closed rectangular section by sequential bending on multi-roll roll-forming mills with longitudinally welding of edges at finishing have proved to be satisfactory $[1,10,13,17]$.

The improvement of designs, process of production and quality control of these products is constantly given considerable attention due to their high importance and adaptation to different ranges of use. Therefore, the development of methods of modeling of the section behavior of various (including improved) structures remains extremely relevant $[4-7,18-20]$, because allows to identify the advantages and disadvantages of new solutions and develop recommendations for improving the processes of manufacturing structural sections. Research on stiffness of structural sections is conducted by bending and torsion tests.

The bending tests are carried out according to standardized methods by loading sections by four-point or three-point scheme [4, 18]. It is quite common to combine experimental tests with computer simulation of the test process $[4,19,21]$. The latter requires an account of the physical conditions of the test deformation, the complexity of the geometric shapes of the section and the material properties of the specimens to be as accurate as possible, which presents certain difficulties [4-6, 1822]. Studies of the complex characteristics of strength and stiffness are performed for sections of different shapes (open and closed) [23], of different materials (including non-metal) [24, 25], non-welded and welded $[19,24,26,27]$, taking into account the complexity of

Corresponding author: kvv.mariupol@gmail.com 
the shape of the final product, location and load in real construction [23, 26, 27]. This defines the deflection values as the characteristics of sections stiffness, and magnitudes of stresses as characteristics of sections strength. Certain progress has been made in testing and modeling the section loading process by three-point bending, when the section is viewed as a beam supported on round supports (pins) and loaded along the axis of symmetry by a rounded loading pin. As a result, the behavior of the walls and webs (faces) of the section, different buckling shapes [18, 23], revealed critical values of forces and stresses have been described. The main result of the tests on the stiffness of the sections is to obtain a graphical dependence of the deflection values on the load force [18-22]. In some cases, instead of the deflection values, they determine the parameters of the beam curvature [5] at loading or analytically calculate the bending angle between the bent beam and the horizontal axis [28]. It is particularly difficult to consider the multilayer sections when using coated specimens $[22,25]$.

Torsion test is carried out for structural sections of various designs and materials [29-31], including those hardened by various processes [32-34]. Modern packages for finite element modeling (FEM) make it possible to evaluate the behavior of sections for both static torsion and torsion with the application of various types of loads [35-37]. The main evaluation criterion is to identify the dependence of torsion angle (or equivalent displacement) on the applied torque (or force impact) [27, 29-31, 37, 38]. For basic cases static conditions are usually investigated.

For the production and, accordingly, for testing of structural sections, galvanizing carbon steel is most often used as a material. When testing galvanized steel sections, the thickness of the zinc coating is generally neglected as an absolutely thin film [39]. Changing the design of the structural section [40-42] or introducing of consistent direct-forming with longitudinal welding of the edges of the closed section requires evaluation of the indices of stiffness and strength (stresses) of RHS to identify the advantages or disadvantages of new processes.

\section{Research objectives and methodology}

So, there is a certain enterprise that produces of RHS by direct-forming (DF-RHS) for reinforcing of uPVC window (Fig. 1). According to production plans, it is desirable to establish the series release of RHS by direct-forming with welding of edges (DFW-RHS) in longitudinal seam. Strength and stiffness (stresses and displacements) of the sections should be evaluated by bending and torsion tests for estimate of prospects of material consumption reducing for improved RHS, as a practical value of the research. The results of the study of the behavior of sections of the same shape, but different variants of manufacture, after the tests will allow to establish dependencies between the force \& torque magnitudes and deflection \& displacement, to estimate the section deflect or twist distortions at the same load, and to compare the stresses in the webs, which is a scientific originality of research.

The aim of this work is to determine, using finiteelement modeling of bending and torsion tests, differences in the strength and stiffness performance characteristics of sections with $40 \mathrm{~mm} \times 50 \mathrm{~mm}$ width of webs, manufactured by directly multi-roll forming of steel beam:

(a) 40*50 DF-RHS - as semi-closed section with a gap between the edges not more than $0.5 \mathrm{~mm}$, formed along a middle of the web (face) with a size of $40 \mathrm{~mm}$;

(b) $40 * 50 \mathrm{DFW}-\mathrm{RHS}$ - as closed sections and subsequent welding of the edges with the longitudinal weld on the middle of the web (face) with a size of $50 \mathrm{~mm}$.

Comparing these types of RHS with the gap and the weld will allow to see differences in the behavior of products of similar cross-section and different variants of manufacture with differences in thickness, and, as a consequence, to evaluate the prospects of reducing the material consumption of the DFW-RHS while ensuring equivalent stiffness.

The research of the RHS stress-strain state was performed on a solid-state deformable model using the $\mathrm{CAD} / \mathrm{CAE}$ systems of SolidWorks. The geometric parameters of the model are fully consistent with the full-scale specimens (Fig. 2) and are made in a scale of 1:1 (for geometric similarity).

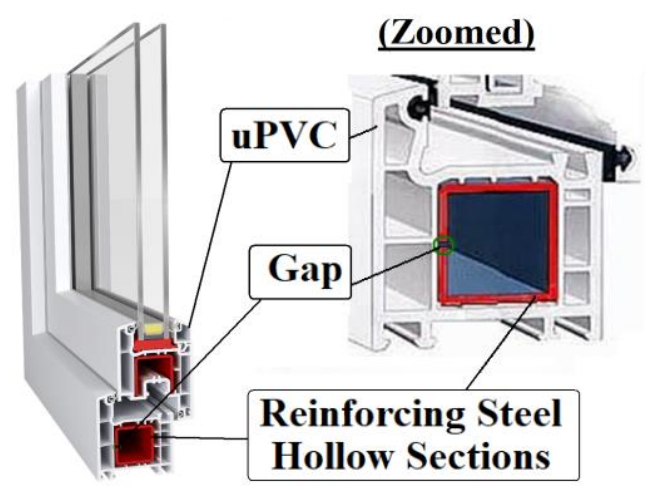

Fig. 1. Reinforcing RHS in uPVC window system.
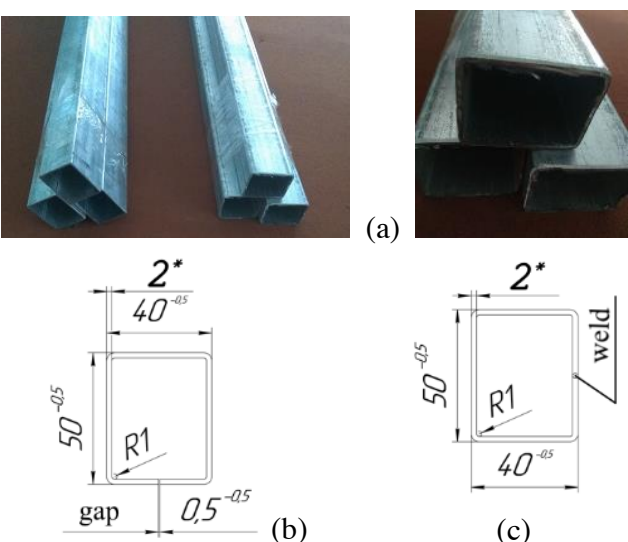

(b)

(c)

Fig. 2. Delivered RHS for research (a), DF-RHS(b) and DFWRHS (c) with webs of $50 \mathrm{~mm} \times 40 \mathrm{~mm}\left({ }^{*} \mathrm{t}=2 \mathrm{~mm}-\right.$ nominal thickness of the section wall). 
The simulation did not take into account the dead weight of the specimen. As an assumption, a RHS wall with weld was considered as solid body without discontinuities, but with insignificant lateral longitudinal cut in the middle of the external web face. The study of the stress-strain state was carried out with loading options for three-point bending (I) and torsion (II). For each option, diagrams of equivalent stresses and linear deflections in the model were determined. The calculated loads and their combinations were taken such that they correspond to the experiment on full-scale specimens.

The specimen models under research: (i) DF-RHS with cross section $40 \mathrm{~mm} \times 50 \mathrm{~mm}$ and thickness of the wall $\mathrm{t}=1.93 \mathrm{~mm}$; (ii) DFW-RHS with cross section $40 \mathrm{~mm} \times 50 \mathrm{~mm}$ and thickness of the wall $\mathrm{t}=1.84 \mathrm{~mm}$; (iii) DFW-RHS with cross section $40 \mathrm{~mm} \times 50 \mathrm{~mm}$ and thickness of the wall $\mathrm{t}=0.7 \mathrm{~mm}$ (validation of results). Plain carbon steel was selected from the standard material library as model material. When calculating these models, the specimen's own weight was not taken into account. In order to find solutions for reducing the RHS material consumption, it is important to have a general picture of the stress-strain state. Obtaining this data is possible by creating a calculated threedimensional model. To determine the actual stress-strain state, FEM was used, which was implemented in the CAD/CAE system environment. A finite element grid was created by "Simulation" means. Obviously, lower stresses, deflection and twist displacement correspond to the strengthliest and stiffest section.

\section{Results and discussion}

\subsection{Three-point bending}

Specimen model was placed horizontally, bottom web is simply supported on supporting pins located at the distance of $1000 \mathrm{~mm}$ (Fig. 3). The finite element mesh of the specimen model is shown in Fig. 3(b). Since the external load acting on the specimen is transmitted through the loading pin, such element with a diameter of $11.8 \mathrm{~mm}$ was taken into account in the model (Fig. 3(c)). The most unfavorable loading options for RHS were considered, leading to maximum deflections at the same force, i.e. loading was acting on a web of $50 \mathrm{~mm}$, see Fig. 3(d),(e). Thus, if DF-RHS was loaded, then the gap was on lateral web of $40 \mathrm{~mm}$; if DFW-RHS was loaded, then the weld was at the bottom web. The applied load $\mathrm{P}(50)=500 \mathrm{~N}$ was act as static in the midpoint between the support pins, at an equal distance of $500 \mathrm{~mm}$ (Fig. 3).

The simulation results are given in Fig. 4 - Fig. 6.

The following was established, as a result of the analysis results of stress-strain state modelling for identical loading schemes and equivalent points of sections:

(i) DFW-RHS with $\mathrm{t}=1.84 \mathrm{~mm}$ compared to DFRHS with $t=1.93 \mathrm{~mm}$ has higher strength. Maximum values of equivalent stress in DFW-RHS with $\mathrm{t}=1.84 \mathrm{~mm}$ were $22 \mathrm{MPa}$ (Fig. 5(a)), and in DF-RHS with $\mathrm{t}=1.93 \mathrm{~mm}-32 \mathrm{MPa}$ (Fig. 4(a));

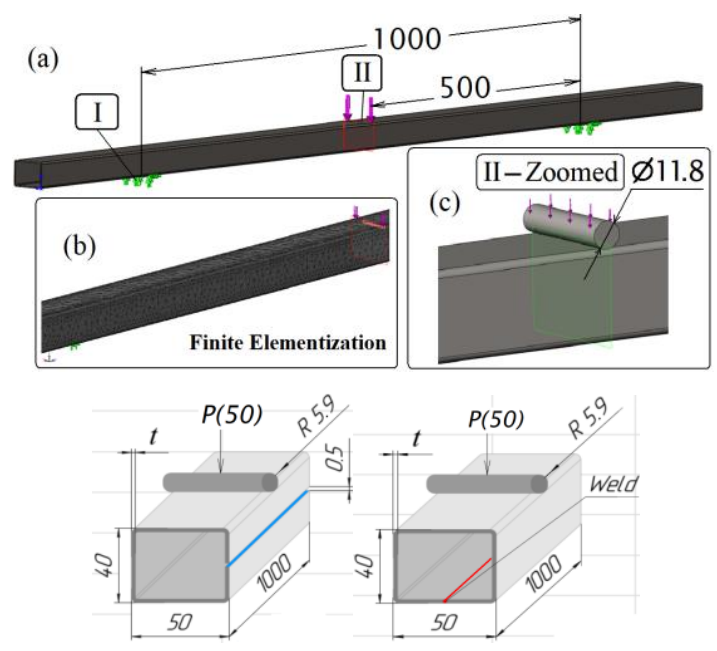

(d)

(e)

Fig. 3. Solid-state model of RHS (a) with supporting (I) and loading (II) pins, illustration of left part finite elementization (b), load acting (c) on DF-RHS (d) and DFWRHS (e) at modelling.
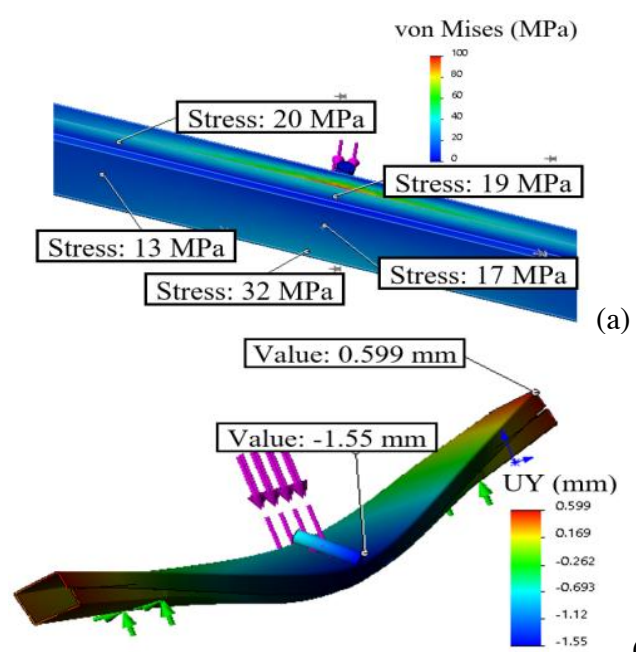

(a)

(b)

Fig. 4. Stresses in the bottom web (a) and deflections (b) of $40 * 50$ DF-RHS, $\mathrm{t}=1.93 \mathrm{~mm}$.

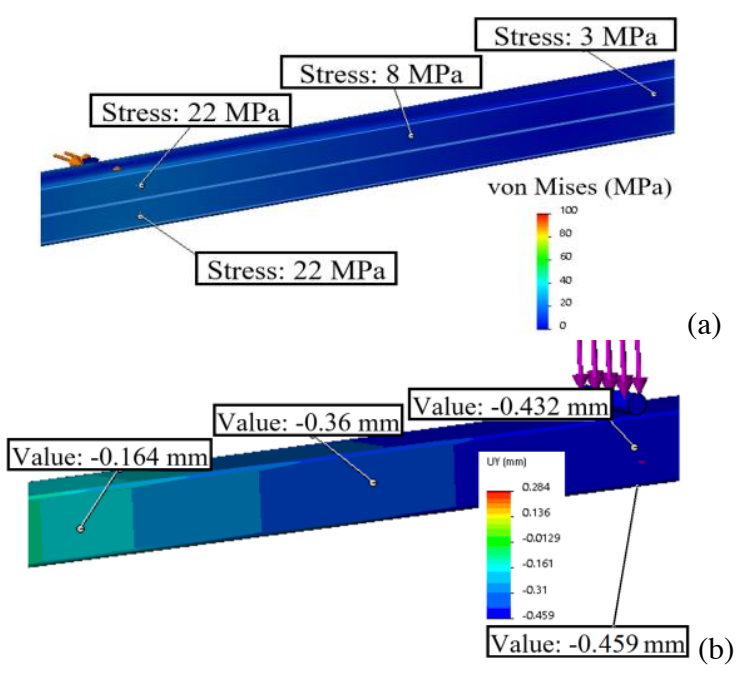

Fig. 5. Stresses in the bottom web (a) and deflections (b) of $40 * 50$ DFW-RHS, $\mathrm{t}=1.84 \mathrm{~mm}$. 


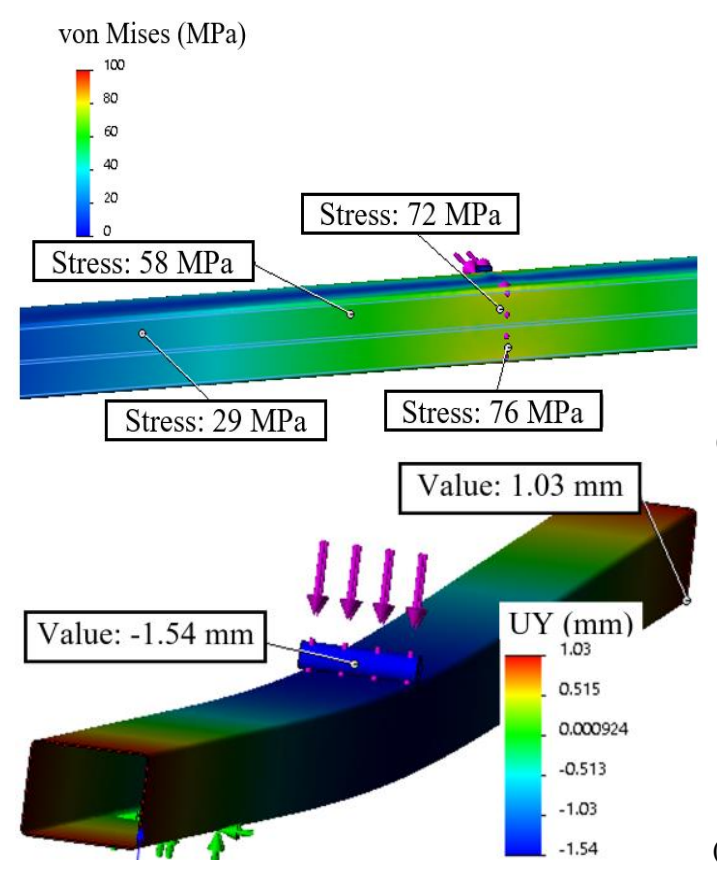

(a)

Fig. 6. Stresses in the bottom web (a) and deflections (b) of $40 * 50$ DFW-RHS, $\mathrm{t}=0.7 \mathrm{~mm}$.

(ii) DFW-RHS with $\mathrm{t}=1.84 \mathrm{~mm}$ compared to DFRHS with $\mathrm{t}=1.93 \mathrm{~mm}$ has higher stiffness. Maximum deflection for DFW-RHS with $\mathrm{t}=1.84 \mathrm{~mm}$ were $f=0.432 \mathrm{~mm}$ (Fig. 5(b)), and for DF-RHS with $\mathrm{t}=1.93 \mathrm{~mm}-f=1.55 \mathrm{~mm}($ Fig. 4(b));

(iii) DFW-RHS with $\mathrm{t}=0.7 \mathrm{~mm}$ compared to DFRHS with $\mathrm{t}=1.93 \mathrm{~mm}$ has a less strength, since maximum equivalent stress in DFW-RHS with $\mathrm{t}=0.7 \mathrm{~mm}$ were $76 \mathrm{MPa}$ (Fig. 6(a)), and in DF-RHS with $\mathrm{t}=1.93 \mathrm{~mm}-32 \mathrm{MPa}$ (Fig. 4(a)). But in this case, the resulting stresses are still much smaller than the yield stress of a given carbon steel $\left(y_{s}=175-195 \mathrm{MPa}\right)$;

(iiii) DFW-RHS with $\mathrm{t}=0.7 \mathrm{~mm}$ compared to DFRHS with $\mathrm{t}=1.93 \mathrm{~mm}$ has slightly greater or equal stiffness, i.e. maximum deflection for DFW-RHS with $\mathrm{t}=0.7 \mathrm{~mm}$ were $f=1.54 \mathrm{~mm}$ (Fig. 6(b)), and for DFRHS with $\mathrm{t}=1.93 \mathrm{~mm}-f=1.55 \mathrm{~mm}$ (Fig. 4(b)).

\subsection{Torsion}

Solid-state models of specimens of considered RHS with a length of $1000 \mathrm{~mm}$ were used in the torsion test modeling. One end of specimen model was fixed at the simulation and torque of $\mathrm{T}=50,000 \mathrm{~N} \cdot \mathrm{mm}$ was applied to the other end. The twist displacement value [43, 44] was estimate for each RHS design, i.e. measured which travel path at the farthest point from the axis of section rotation. Simulation results in the form of distribution of equivalent stresses and twisting displacements for different RHS design are shown in Fig. 7-9.

As a result of modeling the torsion test and analysis of the stress-strain state at the same torques, it should be concluded:

(i) DFW-RHS with $\mathrm{t}=1.84 \mathrm{~mm}$ is more strength than with DF-RHS with $\mathrm{t}=1.93 \mathrm{~mm}$. The maximum equivalent stress in DFW-RHS with $\mathrm{t}=1.84 \mathrm{~mm}$ were
$59 \mathrm{MPa}$ (Fig. 8(a)), and in DF-RHS with $\mathrm{t}=1.93 \mathrm{~mm}-$ $169 \mathrm{MPa}$ (Fig. 7(a)), respectively;

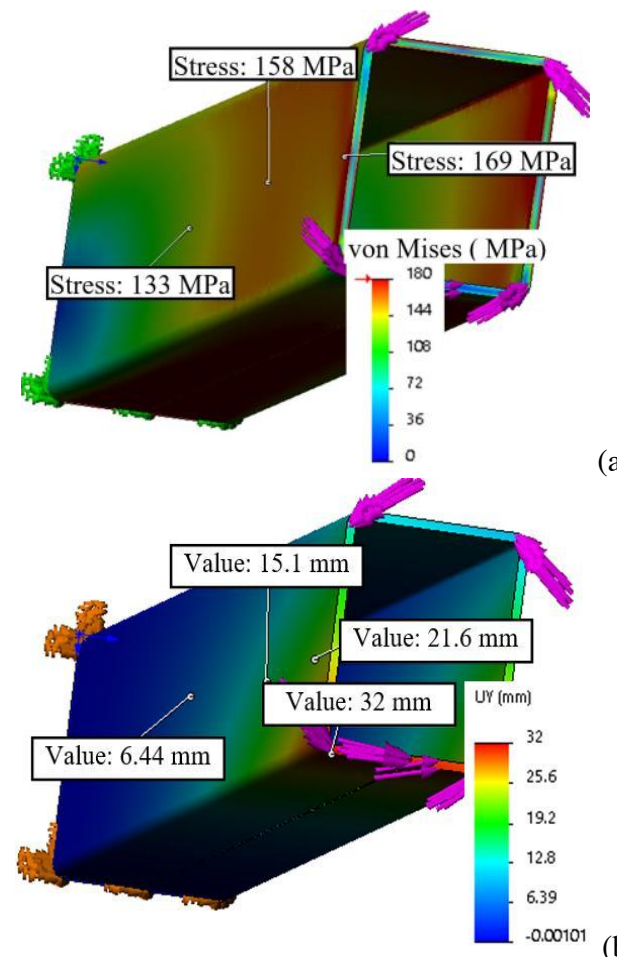

(a)

Fig. 7. Stresses (a) and twist displacements (b) of $40 * 50$ DFRHS, $\mathrm{t}=1.93 \mathrm{~mm}$.

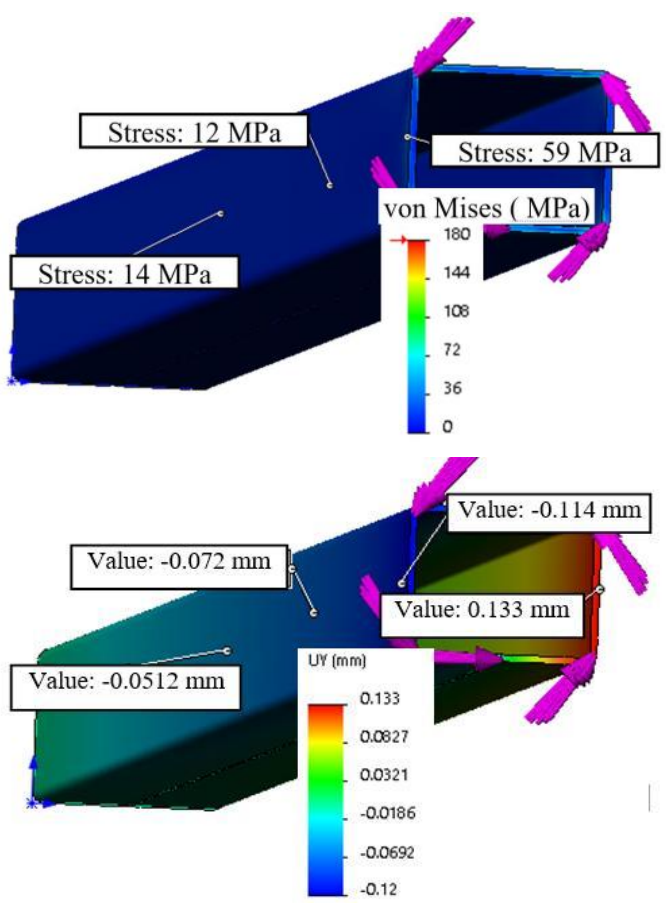

(a)

Fig. 8. Stresses (a) and twist displacements (b) of $40 * 50 \mathrm{DFW}$ RHS, $\mathrm{t}=1.84 \mathrm{~mm}$.

(ii) DFW-RHS with $\mathrm{t}=1.84 \mathrm{~mm}$ is more stiff compared to DF-RHS with $\mathrm{t}=1.93 \mathrm{~mm}$. The maximum values of twist displacements for DFW-RHS with $\mathrm{t}=1.84 \mathrm{~mm}$ were $0.133 \mathrm{~mm}$ (Fig. 8(b)), and for DFRHS with $\mathrm{t}=1.93 \mathrm{~mm}-32 \mathrm{~mm}$ (Fig. 7(b)), respectively; 
(iii) DFW-RHS with $\mathrm{t}=0.7 \mathrm{~mm}$ is more strength than DF-RHS with $t=1.93 \mathrm{~mm}$. The maximum values of equivalent stress in DFW-RHS with $t=0.7 \mathrm{~mm}$ were $118 \mathrm{MPa}$ (Fig. 9(a)), and in DF-RHS with $\mathrm{t}=1.93 \mathrm{~mm}-$ $169 \mathrm{MPa}$ (Fig. 7(a)), respectively;

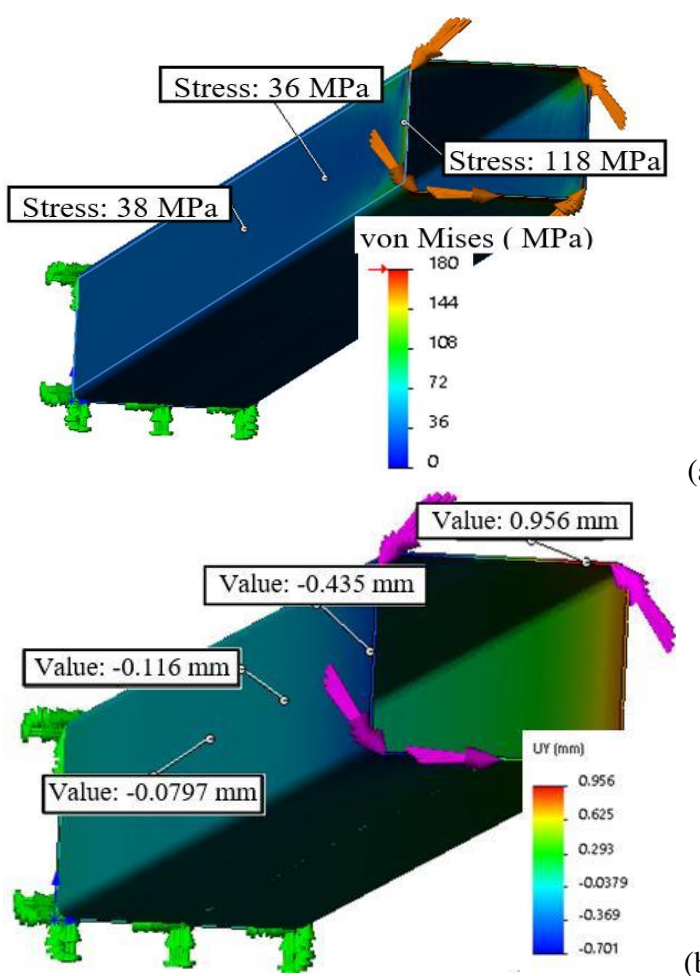

(a)

(b)

Fig. 9. Stresses (a) and twisting displacements (b) of $40 * 50$ DFW-RHS, $\mathrm{t}=0.7 \mathrm{~mm}$.

(iiii) DFW-RHS with $\mathrm{t}=0.7 \mathrm{~mm}$ is more stiff compared to DF-RHS with $\mathrm{t}=1.93 \mathrm{~mm}$. The maximum twist displacement for DFW-RHS with $\mathrm{t}=0.7 \mathrm{~mm}$ were $0.956 \mathrm{~mm}$ (Fig. 9(b)), and for DF-RHS with $\mathrm{t}=1.93 \mathrm{~mm}-32 \mathrm{~mm}$ (Fig. 7(b)), respectively.

\section{Conclusions}

Based on the FEM using, RHS with a cross section of $40 \mathrm{~mm} \times 50 \mathrm{~mm}$ was investigated, that have a difference in manufacturing options by direct-forming (DF-RHS) with longitudinal gap and direct-forming with the next edge welding (DFW-RHS) into longitudinal weld seam. It was found that the existing initial differences affect to the results: (a) the gap at DF-RHS is located in the middle of the width of the smaller web $(40 \mathrm{~mm})$, and the weld seam at DFW-RHS is in the middle of the width of the larger web $(50 \mathrm{~mm})$; (b) the average wall thickness of DF-RHS is $t=1.93 \mathrm{~mm}$, and DFW-RHS is $\mathrm{t}=1.84 \mathrm{~mm}$ (i.e. the difference is $4.8 \%$ ).

Based on the proposed methodology for three-point bending test and torsion test, the distribution of equivalent stresses and displacements in RHS was analyzed. It is shown that the use of DFW-RHS as a reinforcing beam has advantages (especially in terms of stiffness) compared to DF-RHS. It was found that with identical loading schemes, DF-RHS with $t=1.93 \mathrm{~mm}$ has the same stiffness characteristics as a DFW-RHS with $\mathrm{t}=0.7 \mathrm{~mm}$, i.e. it becomes possible to reduce metal consumption by $62 \%$.

Strength of DFW-RHS with $\mathrm{t}=0.7 \mathrm{~mm}$ are worse than DF-RHS with $\mathrm{t}=1.93 \mathrm{~mm}$ due to a significant difference in wall thickness, however, the maximum bending stresses in DFW-RHS with $\mathrm{t}=0.7 \mathrm{~mm}$, equal to $77 \mathrm{MPa}$, i.e. do not exceed the yield strength of the section steel $\left(\mathrm{y}_{\mathrm{s}}=175-195 \mathrm{MPa}\right)$.

For the most unfavorable loading for DF-RHS to the wider web $(50 \mathrm{~mm})$, when the unwelded gap is on the lateral web, the forming a weld gives an improvement in stiffness at least $50 \%$. That is, despite the smaller wall thickness, DFW-RHS is operationally stable under the most unfavorable load case.

Thus, changing the manufacturing process from DFRHS to DFW-RHS will improve stiffness and keep strength values at a sufficient level.

It should be noted that there are limitations in the interpretation of the results of these research, via tests were carried out on RHS with a discontinuity (gap or weld) formed on different lateral webs. This is due to the fact that the RHS manufacturer enterprise supplied samples of such a design. In the prospect, testing of similar size RHS but different production options with a formed gap or weld on similar lateral webs (as a rule, on a smaller webs of $40 \mathrm{~mm}$ for this case), will make the evaluation more adequate. It will also be interesting to compare the simulation results and experimental tests.

\section{References}

1. J. Wardenier, etc, Hollow sections in structural applications (Geneva: CIDECT, 2010)

2. M. M. Moroz, S. O. Korol, S. M. Chernenko, Y. O. Boiko, O. M. Vasylkovskyi, International Journal of Engineering and Technology(UAE).7(4), 135-139 (2018)

3. V. Artiukh, V. Mazur, L. Shilova, MATEC Web of Conferences 106, 03002 (2017)

4. Y.Huang, B. Young, Thin-walled Structures 73, 216-228 (2013)

5. J. Wang, S. Afshan, M. Gkantou, M. Theofanous, C. Baniotopoulos, L. Gardner, Journal of Constructional Steel Research 121, 97-109 (2016)

6. A. N. Lubenets, E. N. Smirnov, V. V. Shcherbachev, Stal' 8, 102-106 (2002)

7. R. Puzyr, V. Kukhar, A. Maslov, Y. Shchipkovskyi, International Journal of Engineering \& Technology (UAE) 7(4.3), 30-34 (2018)

8. V. Kukhar, E. Balalayeva, A. Prysiazhnyi, O. Vasylevskyi, I. Marchenko, MATEC Web of Conferences 178, 02003 (2018)

9. V. Sikulskiy, V. Kashcheyeva, Y. Romanenkov, A. Shapoval, Eastern-European Journal of Enterprise Technologies 4(1)(88), 43-49 (2017)

10. G. A. Orlov, Metallurgist 58(11-12), 1001-1005 (2015)

11. R. Puzyr, D. Savelov, V. Shchetynin, R. Levchenko, T. Haikova, S. Kravchenko, S. Yasko, R. Argat, 
Y. Sira, Y. Shchipkovakyi, Eastern-European Journal of Enterprise Technologies 4(1-94), 55-60 (2018)

12. N. S. Hrudkina, L. I. Aliieva, Modeling of cold extrusion processes using kinematic trapezoidal modules, FME Transactions 48(2), 357-363 2020

13. M.Sun, J.A. Packer, Journal of Constructional Steel Research 92, 67-78 (2014)

14. L. Gardner, N. Saari, F. Wang, Thin-Walled Structures 48(7), 495-507 (2010)

15. V. V. Kukhar, A. V. Grushko, I. V. Vishtak, Solid State Phenomena 284, 408-415 (2018) .

16. V. Kukhar, O. Kurpe, E. Klimov, E. Balalayeva, V. Dragobetskii, International Journal of Engineering \& Technology (UAE) 7(4.3), 35-39 (2018)

17. Forming Technology of Cold Rolling Square Rectangular Tube and Prospect on New Technology 4, http://www.rishbin.com/services/cold-rollingsquare-rectangular-tube-technology.html

18. M. Bock, I. Arrayago, E. Real, Journal of constructional steel research 109, 13-23 (2015)

19. V. A. Osadchii, S. M. Gorbatyuk, D. I. Filippov, N. S. Kuprienko, Metallurgist 63, 658-664 (2019)

20. O. E. Markov, O. V. Gerasimenko, A. A. Shapoval, O. R. Abdulov, R. U. Zhytnikov, International Journal of Advanced Manufacturing Technology 103(5-8), 3057-3065 (2019)

21. A. Podstawka, M. Kovar, M. Foglar, V. Kristek, Advanced Materials Research 1106, 118-121 (2015)

22. A. K. Singh, R. Tyagi, V. Ranjan, P. Sathujoda, Vibroengineering PROCEDIA 21, 248-252 (2018)

23. Y.-L. Li, Y.-Q. Li, Z.-Y. Shen, Thin-Walled Structures 107, 66-79 (2016)

24. P. W. Laksono, T. Rochman, H. Setyanto, E. Pujiyanto, K. Diharjo, Advanced Materials Research 893, 504-507 (2014)

25. J. H. Chen, W. S. Luo, Micromachines 8(7), 206 (2017)

26. K. Kuchta, I. Tylek, MATEC Web of Conferences 163, 07005 (2018)

27. O. S. Anishchenko, V. V. Kukhar, A. V. Grushko, I. V. Vishtak, A. H. Prysiazhnyi, E. Yu. Balalayeva, Materials Science Forum 945, 531-537 (2019)

28 K. Benedyk, Proc. IDDRG 2012: Lightweight: Possibilities \& Challenges, 203-215 (2012)
29. S. V. Devi, T. G. Singh, K. D. Singh, Journal of Constructional Steel Research 162122, 105730 (2019)

30. T. Tafsirojjaman, S. Fawzia, D. Thambiratnam, X. L. Zhao, Structures 24, 610-626 (2020)

31. A. Amin, E. C. Bentz, Structural Concrete 19(3), 684-694 (2018)

32. Yu. G. Chabak, V. I. Fedun, T. V. Pastukhova, V. I. Zurnadzhy, S. P. Berezhnyy, V. G. Efremenko, Problems of Atomic Science and Technology 110(4), 97-102 (2017)

33. V.E. Vaganov, A. V. Aborkin, M. I. Alymov, V.D. Berbentsev, Russian Metallurgy (Metally) 9, 732-738 (2015)

34. V. B. Tarelnyk, O. P. Gaponova, I. V. Konoplianchenko, N. S. Evtushenko, V. A. Herasymenko, Metallofiz. Noveishie Tekhnol. 40(2), 235-254 (2018)

35. S. Gunalan, M. Mahendran, Thin-Walled Structures 73, 1-17 (2013)

36. I. P. Shats'kyi, O. M. Lyskanych, V. A. Kornuta, Materials Science 48(3), 469-472 (2016)

37. T. Sputo, J. Tovar Thin-Walled Structures 43(12), 1852-1881 (2005)

38. A. Anishchenko, V. Kukhar, V. Artiukh, O. Arkhipova, MATEC Web of Conferences 239, 06007 (2018)

39. I. P. Shatskyi, M. V. Makoviichuk, A. B. Shcherbii, 2017 Proc. 11th Int. Conf. on Shell Structures: Theory and Applications (SSTA 2017) (11-13 October 2017, Gdansk, Poland) 4, 165-168 (2017)

40. O. Markov, O. Gerasimenko, L. Aliieva, A. Shapoval, M Kosilov, Eastern-European Journal of Enterprise Technologies 2(1)(98), 39-46 (2019)

41. V. Dragobetskii, E. Naumova, A. Shapoval, S. Shlyk, D. Moloshtan, Proc. Int. Conf. on Modern Electrical and Energy Systems (MEES 2019) (23-25 Sept. 2019, Kremenchuk, Ukraine) 506-509 (2019)

42. M. A. Castellucci, I. Pillinger, P. Hartley, G. T. Deeley, Thin-Walled Structures 29(1-4), 159174 (1997)

43. K. Yoon, P.-S. Lee, Structural Engineering and Mechanics 43(4), 411-437 (2012)

44. A. Wang, H. Xue, E. Bayraktar, Y. Yang, S. Saud, P. Chen, Metals 10(1), 31 (2019) 